\title{
Nivel de higiene y prevalencia de Porphyromona gingivalis y Fusobacterium nucleatum en pacientes recuperados de SARS-CoV-2.
}

\author{
Hygiene level and prevalence of Porphyromona gingivalis and \\ Fusobacterium nucleatum in recovered SARS-CoV-2 patients.
}

\author{
Janeth Lizett Rodríguez-Cardona,* Wendy J Álvarez-Fernández, ${ }^{\ddagger}$ Jany A Jiménez-Del Valle, ${ }^{\S}$ M Elisa Sánchez-Dorado, ${ }^{\natural}$ \\ Víctor H Urrutia-Baca," Arturo A Cienfuegos-Sarmiento," Myriam A De la Garza-Ramos**
}

\section{RESUMEN}

Introducción: El SARS-CoV-2 afecta el sistema respiratorio en diferentes grados. La cavidad oral es el lugar más colonizado por bacterias, por lo tanto, al no tener una adecuada higiene pueden presentarse diferentes enfermedades secundarias, lo que ha causado alerta en el gremio odontológico, ya que puede contribuir a complicaciones posteriores en los pacientes. Material y métodos: El estudio fue conformado por 47 pacientes voluntarios recuperados de SARS-CoV-2, residentes de Montemorelos, Nuevo León, México, donde fueron atendidos en Bucalia Dent, consultorio dental. Después del consentimiento informado de cada paciente, se realizó una historia clínica para conocer los síntomas, enfermedades sistémicas, ausencia de dientes y nivel de inflamación gingival de acuerdo al índice de Loe y Silness. A continuación, se tomó una muestra de biofilm microbiano (placa dentobacteriana), la cual se suspendió en una solución buffer de fosfato, posteriormente fue llevada al Centro de Investigación y Desarrollo en Ciencias de la Salud (CIDICS), Monterrey, N.L, México. Se extrajo DNA y se purificó, después se realizó PCR para detectar los patógenos orales; la PCR se visualizó en gel de agarosa (1.5\%) por tinción de bromuro de etidio. Resultados: Se detectó $80.85 \%$ Porphyromona gingivalis y $68.09 \%$ Fusobacterium nucleatum en pacientes recuperados de SARS-CoV-2; 23.4\% presentaron inflamación leve de acuerdo al índice de Loe y Silness, $54.5 \%$ fueron masculinos y $45.5 \%$ femeninos. Por otro lado, $36.4 \%$ de los pacientes con inflamación leve tenían de cuatro a seis dientes ausentes. En estos
ABSTRACT

Introduction: SARS-CoV-2 affects the respiratory system to different degrees. The oral cavity is a colonized place by bacterias, therefore, by not having good hygiene, different secondary diseases can occur; this has caused an alert in the dental industry, since it can contribute to later complications in patients. Material and methods: The study was conducted in 47 SARS-CoV-2 recovered volunteers from the Montemorelos city of the Nuevo León state, Mexico, who were attended at the Bucalia Dent dental clinic. An informed consent was obtained from each of the patients, then their clinical history was documented in order to know the symptoms, previous systemic diseases, absence of teeth and degree of gingival inflammation, as suggested by Loe and Silness. Subsequently, a dental plaque sample was taken from all patients, which was suspended in a phosphate buffered solution and shipped to The Center for Research and Development in Health Sciences (CIDICS), Monterrey, NL, Mexico for storage. DNA extraction and purification was performed and PCR was carried out for the oral pathogens detection. All PCR products were visualized on 1.5\% agarose gel by ethidium bromide staining. Results: Porphyromona gingivalis and Fusobacterium nucleatum were detected in $80.85 \%$ and $68.09 \%$ of SARS-CoV-2 recovered patients, respectively. $23.4 \%$ showed mild inflammation based on the Loe and Silness criteria, $54.5 \%$ were male and $45.5 \%$ female. On the other hand, $36.4 \%$ of patients with mild inflammation had between 4 to 6 missing teeth. A single

\footnotetext{
* Estudiante de odontología, Universidad de Montemorelos, Nuevo León, México.

¥ Profesor, Escuela de Ciencias Estomatológicas, Universidad de Montemorelos, Nuevo León, México.

§ Centro de investigación, Escuela de Ciencias Estomatológicas, Universidad de Montemorelos, Nuevo León, México.

" Facultad de Ciencias Biológicas, Universidad Autónoma de Nuevo León, Nuevo León, México.

" Investigación, Centro de Investigación y Desarrollo en Ciencias de la Salud, Nuevo León, México.

** Microbióloga, Universidad Autónoma de Nuevo León, Nuevo León, México.

Recibido: 09 de agosto de 2021. Aceptado: 09 de noviembre de 2021.
}

Citar como: Rodríguez-Cardona JL, Álvarez-Fernández WJ, Jiménez-Del Valle JA, Sánchez-Dorado ME, Urrutia-Baca VH, Cienfuegos-Sarmiento AA et al. Nivel de higiene y prevalencia de Porphyromona gingivalis y Fusobacterium nucleatum en pacientes recuperados de SARS-CoV-2. Rev ADM. 2021; 78 (6): 309-313. https://dx.doi.org/10.35366/102972 
pacientes se detectó $18.18 \%$ únicamente con Fusobacterium nucleatum y $27.27 \%$ sólo con Porphyromona gingivalis; el sexo masculino tuvo predisposición en $66.6 \%$ y el femenino en $33.33 \%$. Se observó infección con los dos patógenos presentes en $45.45 \%$; y $60 \%$ de estos pacientes fueron masculinos. Conclusiones: Los pacientes recuperados de SARSCoV-2 analizados en esta investigación mostraron mala higiene oral y alta prevalencia de los patógenos mencionados altamente relacionados a inflamación gingival o enfermedad periodontal, lo que nos indica que es indispensable la intervención del odontólogo al finalizar el periodo de infección de cada paciente.

Palabras clave: SARS-CoV-2, bacterias, Porphyromona gingivalis, Fusobacterium nucleatum, higiene oral, inflamación gingival. infection by Fusobacterium nucleatum was detected in $18.18 \%$ and by Porphyromona gingivalis in $27.27 \%$; the male sex had a predisposition with $66.66 \%$ and $33.33 \%$ female; coinfection of both pathogens was observed in $45.45 \%$ where $60 \%$ were male. Conclusions: SARS-CoV-2 recovered patients show poor oral hygiene and a high prevalence of oral pathogens related to the development of inflammatory gingival or periodontal disease, this suggests the need for an odontological clinical intervention at the end of the course of infection or disease caused by SARS-CoV-2.

Keywords: SARS-CoV-2, bacteria, Porphyromona gingivalis, Fusobacterium nucleatum, oral hygiene, gingival inflammation.

\section{INTRODUCCIÓN}

$A^{p}$ principios del año 2020, la Organización Mundial de la Salud (OMS) reconoció al nuevo virus respiratorio como síndrome agudo respiratorio severo de coronavirus 2 (SARS-CoV-2) y se identificó como el agente causante de un grupo de casos de neumonía. El primer caso en México se detectó el 27 de febrero de 2020 en la Ciudad de México. En esos momentos el ritmo de la mortalidad era incierto; en mayo de 2020 se conocieron aproximadamente 3.5 millones de casos y 250,000 muertes alrededor del mundo. Este nuevo virus forma parte del betacoronavirus y comparte con el SARS-CoV una unión a la enzima convertidora de angiotensina-2 (ACE-2), una exopeptidasa de membrana que actúa no sólo como receptor de estos virus, sino que también les permite entrar en las células humanas; una vez dentro del huésped, puede mutar, posiblemente debido al fuerte estrés inmunológico al que es sometido. ${ }^{1-8}$

El SARS-CoV-2 altera el sistema inmunológico, causando distintos cambios en las reacciones de respuesta que pueden volverse contra el huésped, lo que lleva a un daño autoinmune, particularmente al tejido conectivo de los pulmones; aunque no está confirmado, hipotéticamente, podría haber un vínculo entre la localización epitelial de la proteína ACE2 en mucosa oral, mucosa nasal y la nasofaringe como receptor funcional para el coronavirus. ${ }^{9,10}$

Existen al menos tres vías diferentes donde se manifiesta el virus: en el tracto respiratorio superior e inferior, entrando en la cavidad oral en forma de pequeñas gotas; en la sangre entrando en la boca mediante el líquido crevicular en la encía y por infección de las glándulas salivales mayores y menores con la liberación subsecuente de las partículas en la saliva mediante los conductos salivares. ${ }^{11}$
Los pulmones son similares a la cavidad bucal, se le denomina «comunidad ecológica de comensales, simbióticos y organismos patógenos». La inmigración microbiana y la eliminación es constante entre la cavidad oral y los pulmones, lo que permite salud y distribución microbiótica. La infección respiratoria inferior se inicia por la contaminación del epitelio de las vías respiratorias inferiores por inhalación de microorganismos englobados en gotas aerosolizadas o por aspiración de secreciones orales asociado con enfermedad bucal (las cuales contienen microorganismos como P. gingivalis, F. nucleatum, P. intermedia)..$^{12}$

Estudios indican que este nuevo coronavirus posee la capacidad de alterar el equilibrio de la microbiota oral, lo que combinado con un sistema inmune deprimido permitiría la colonización por infecciones oportunistas, ya que la cavidad oral ofrece el perfecto portal de entrada a virus y bacterias del medio ambiente, por lo tanto, es uno de los hábitats más densamente poblados del cuerpo humano; por lo que podría existir colonización intracelular en células epiteliales de la cavidad oral por complejos bacterianos constituidos por Aggregatibacter actinomycetemcomitans, Porphyromonas gingivalis y Tannerella forsythia. ${ }^{13-15}$ Dado que la mucosa oral podría ser la primera área infectada con SARS-CoV-2, podría plantearse la hipótesis de que las lesiones y manifestaciones de la mucosa oral podrían ser los primeros signos que aparecen. ${ }^{16-22}$

No existe una gran diferencia entre las recomendaciones para el tratamiento de las neumonías por otros virus y la neumonía por SARS-CoV-2. La indicación empírica de antibióticos cuando se sospecha sobreinfección bacteriana debe iniciarse en forma temprana. ${ }^{12,23}$

La obtención de ácido desoxirribonucleico (DNA) es el punto de partida para la mayoría de análisis genéticos; incluso, contando con pequeñas cantidades de DNA, es 
posible amplificar genes específicos in vitro a través de la reacción en cadena de la polimerasa. Por otro lado, la PCR es una técnica para la síntesis in vitro de secuencias específicas de DNA. La técnica de PCR se convirtió prácticamente en un estándar en odontología; se basa en la capacidad de la enzima Taq DNA polimerasa para sintetizar una nueva cadena de DNA complementaria a la hebra molde. ${ }^{24-28}$

Las bacterias como Porphyromonas gingivalis que pasan por aspiración a las mucosas respiratorias pueden ser reconocidas por las células de la inmunidad natural a través de receptores; Fusobacterium nucleatum forma parte de la microbiota orofaríngea, gastrointestinal y genitourinaria; según las circunstancias clínicas puede tener actividad patogénica, es así como en lesiones periodontales, como gingivitis, periodontitis o en procedimientos dentales, se ha identificado como posible fuente de bacteriemia e infecciones invasivas. En pacientes adultos hay reportes de infecciones pleuropulmonares asociadas a problemas odontológicos cuando se producen broncoaspiraciones asociadas a mal estado bucodental. Es común que las infecciones virales respiratorias predisponen a los pacientes a sobreinfecciones bacterianas, lo que puede llevar al aumento de la gravedad y mortalidad de la enfermedad. Otros estudios sobre el coronavirus han demostrado que es más fuerte la adherencia estreptocócica a las células epiteliales en el tracto respiratorio, causando complicaciones como neumonía. Se reportó que en casos graves de SARS-CoV-2 la sobreinfección bacteriana es común, esto es apoyado por la investigación de Zheng, quien señala que $50 \%$ de los pacientes con SARS-CoV-2 severo murió con la presencia de una infección bacteriana secundaria. ${ }^{12,29-31}$

\section{MATERIAL Y MÉTODOS}

Toma de muestra. Se realizó una historia clínica con preguntas clave para conocer el estado del paciente durante su desarrollo del SARS-CoV-2, acompañada de un examen intraoral así como una inspección de acuerdo al índice gingival de Loe y Silness. Con un palillo estéril se tomó una muestra del biofilm (placa dentobacteriana) de la zona retromolar y se colocó en un tubo eppendorf de $1.5 \mathrm{~mL}$ con buffer de fosfato, sellando la muestra con parafina, la cual fue procesada en el Centro de Investigación y Desarrollo en Ciencias de la Salud (CIDICS).

Extracción y preparación del DNA. El tubo de 1.5 $\mathrm{mL}$ fue introducido en la centrífuga a 12,000 revoluciones por 10 min para obtener la pastilla del DNA.
Se añadió $1 \mathrm{~mL}$ de Trizol por pipeteo repetido y $2 \mu \mathrm{L}$ de cloroformo, se homogeneizó por medio del vórtice durante $15 \mathrm{~s}$, con un reposo de 10 min para después centrifugar durante el mismo tiempo. Posteriormente, se dividió en tres fases: acuosa (RNA), interfase DNA), orgánica (proteínas y resto de trizol).

Se recopiló la interfase (DNA) en un tubo diferente de $1.5 \mathrm{~mL}$. Se añadió $500 \mu \mathrm{L}$ de etanol absoluto para eliminar las impurezas, dejándolo reposar por 3 min y centrifugando nuevamente; se descartó el sobrenadante, se lavó y centrifugó dos veces con $1 \mathrm{~mL}$ de citrato trisódico. Se descartó el sobrenadante y se resuspendió en $1.5 \mathrm{~mL}$ de etanol a $70 \%$, se reposó entre $10-20 \mathrm{~min}$ y centrifugó; por último se retiró el sobrenadante y se agregó $\mathrm{PBS}+\mathrm{BSA}$ al $0.5 \%$.

Reacción en la cadena polimerasa (PCR). Se utilizó dNTP mix:

1. dGTP (trifosfato de desoxiguanosina).

2. dTTP (trifosfato de timidina).

3. dATP (trifosfato de desoxiadenosina).

4. dCTP (trifosfato de desoxicitidina).

Se preparó un volumen inicial de $500 \mu \mathrm{L}$; en un tubo de $1.5 \mathrm{~mL}$ se introdujo $50 \mu \mathrm{L}$ de cada reactivo de dNTP mix y se agregaron $300 \mu \mathrm{L}$ de $\mathrm{H}_{2} \mathrm{O}$.

En un tubo de $1.5 \mathrm{~mL}$ se realizó la preparación de los primers $10 \mu \mathrm{L}$ de Forward (Fv) y $10 \mu \mathrm{L}$ de Reverse (Rv), agregando $90 \mu \mathrm{L}$ de $\mathrm{H}_{2} \mathrm{O}$ respectivamente; estos actúan como cebadores de la acción de polimerasa.

El listado anterior indica los volúmenes necesarios para una muestra, por lo tanto estos valores fueron multiplicados por 47 que fue el número de nuestras muestras.

Se tomaron tubos de $10 \mathrm{mg}$ de acuerdo al número de muestras; a cada uno se agregó $23 \mu \mathrm{L}$ de reacción final de reacción en la cadena polimerasa (PCR) y $2 \mu \mathrm{L}$ de DNA respectivo a cada paciente. Posteriormente, las muestras se colocaron en el termociclador para realizar los ciclos de temperaturas necesarios para la amplificación de PCR.

Electroforesis en gel de agarosa. En un matraz se rebajó el TAE 10x con 10 y $90 \mathrm{~mL}$ de $\mathrm{H}_{2} \mathrm{O}$, se agregó $1.5 \mathrm{~g}$ de agarosa, se colocó el matraz en la plancha durante cinco min aproximadamente, verificando que todo se integrara; el líquido obtenido de agarosa se colocó en la base de la cámara de electroforesis con sus respectivas celdas para gelificar; una vez gelificado se introdujo a la cámara el buffer de carga, asegurándose de cubrir todo el gel. 
En la primera celda se depositó $1 \mu \mathrm{L}$ de colorante, 1 $\mu \mathrm{L}$ de buffer blue y $5 \mu \mathrm{L}$ de leadder; en la segunda celda $1 \mu \mathrm{L}$ de colorante, $1 \mu \mathrm{L}$ de buffer blue y $5 \mu \mathrm{L}$ de PCR de la bacteria; en las siguientes celdas $1 \mu \mathrm{L}$ de colorante, $1 \mu \mathrm{L}$ de buffer blue y $5 \mu \mathrm{L}$ de PCR de los pacientes respectivos. Para observar los resultados claramente, se introdujo el gel al Bio-Rad, Gel Doc ${ }^{\text {TM }}$ XR.

\section{RESULTADOS}

Se detectó en los pacientes recuperados de SARS-CoV-2 de esta investigación $80.85 \%$ Porphyromona gingivalis y $68.09 \%$ Fusobacterium nucleatum; $23.4 \%$ mostraron inflamación leve de acuerdo al índice de Loe y Silness; de estos pacientes, $54.5 \%$ fueron del sexo masculino y $45.5 \%$ del femenino. Por otro lado, $36.4 \%$ de los pacientes que tuvieron inflamación leve, presentaron de cuatro a seis dientes ausentes; $18.18 \%$ de los pacientes mostraron únicamente Porphyromona gingivalis y $27.27 \%$ Fusobacterium nucleatum; el sexo masculino tiene una predisposición de una enfermedad gingival de $66.66 \%$ y el sexo femenino de $33.33 \%$. Los dos patógenos mencionados se observaron en $45.45 \%$ en el sexo femenino y $60 \%$ en el masculino.

\section{DISCUSIÓN}

Nos encontramos en un campo desconocido en relación al SARS-CoV-2.

Sabemos que una de las entradas principales del virus es la cavidad oral, por lo tanto, la higiene bucal es esencial para minimizar el riesgo de adquirir el virus. En esta investigación decidimos concentrarnos en las bacterias principales de la enfermedad periodontal así como en la enfermedad respiratoria.

Está comprobado que pacientes con mayor número de bacterias en boca están predispuestos a desarrollar una enfermedad oral así como una enfermedad bacteriana secundaria.

Esta investigación queda abierta para continuar con los estudios de diferentes grupos bacterianos en pacientes recuperados, al igual que en pacientes actualmente infectados con SARS-CoV-2 y relacionar las cargas bacterianas entre ambos pacientes.

\section{CONCLUSIONES}

Nos encontramos en un campo desconocido en relación al SARS-CoV-2, es común que las infecciones virales respiratorias predisponen a los pacientes a sobreinfec- ciones bacterianas, lo que puede llevar al aumento de la gravedad y mortalidad de la enfermedad. Sabemos que una de las entradas principales del virus es la cavidad oral, por lo tanto, la higiene bucal es esencial para minimizar el riesgo de adquirir el virus.

En esta investigación decidimos concentrarnos en las bacterias principales de la enfermedad periodontal, así como en la enfermedad respiratoria. Está comprobado que los pacientes con mayor número de bacterias en la boca están predispuestos a desarrollar una enfermedad oral así como una enfermedad bacteriana secundaria.

Esta investigación queda abierta para continuar con los estudios de diferentes grupos bacterianos en pacientes recuperados, al igual que en pacientes actualmente infectados con SARS-CoV-2 y relacionar las cargas bacterianas entre ambos pacientes.

\section{REFERENCIAS}

1. Mijovic B. Covid-19-Lessons learned. Scripta Medica. 2020; 51 (1): 1-5.

2. Ashikujaman Syed. Coronavirus: a mini-review. Int J Curr Res Med Sci. 2020; 6 (1): 8-10.

3. Perlman S. Another decade, another coronavirus. N Engl J Med. 2020; 382 (8): 760-762.

4. Gaitán-Cepeda L, Leyva-Huerta E, Cruz-González R, Carmona-Ruiz D, Rodríguez M, Gómez-Arenas A. COVID-19 y el cirujano dentista. Una revisión integral. Rev Odont Mex. 2019; 23 (4): 207-2015.

5. Abramovitz I, Palmon A, Levy D, Karabucak B, Kot-Limon N, Shay B et al. Dental care during the coronavirus disease 2019 (COVID-19) outbreak: operatory considerations and clinical aspects. Quintessence Int. 2020; 51 (5): 418-429.

6. Suárez V, Suarez-Quezada M, Oros-Ruiz S, Ronquillo-De Jesús E. Epidemiología de COVID-19 en México: del 27 de febrero al 30 de abril de 2020. Rev Clin Esp. 2020; 220 (8): 463-471.

7. Pacheco MPM, Pacheco GJD, Hernández MAB et al. Consideraciones sobre el diagnóstico de COVID-19 y el papel del diagnóstico salival. Rev ADM. 2020; 77 (4): 191-196.

8. Dantas-Soares C, Andrade-de Carvalho R, Andrade-de Carvalho K, Goretti-Freire M, Paes-de Almeida O. Letter to editor: oral lesions in a patient with Covid-19. Med Oral Patol Oral Cir Bucal. 2020; 25 (4): e563-e564.

9. Dziedzic A, Wojtyczka R. The impact of coronavirus infectious disease 19 (COVID-19) on oral health. Oral Dis. 2021; 27 Suppl 3: 703-706. doi: 10.1111/odi.13359.

10. Amorim-Dos Santos J, Normando A, Carvalho-da Silva R, De Paula R, Cembranel A, Santos-Silva A et al. Oral mucosal lesions in a COVID-19 patient: New signs or secondary manifestations? Int J Infect Dis. 2020; 97: 326-328.

11. Baghizadeh Fini M. What dentists need to know about COVID-19. Oral Oncol. 2020; 105: 104741.

12. Sampson V, Kamona N, Sampson A. Could there be a link between oral hygiene and the severity of SARS-CoV-2 infections? Br Dent J. 2020; 228 (12): 971-975.

13. Cruz-Quintana S, Díaz-Sjostrom P, Arias-Socarrás D, MazónBaldeón G. Microbiota de los ecosistemas de la cavidad bucal. Rev Cubana Estomatol. 2017; 54 (1): 84-99. 
14. Serrano-Coll HA, Sánchez-Jiménez M, Cardona-Castro N. Conocimiento de la microbiota de la cavidad oral a través de la metagenómica. Rev CES Odont. 2015; 28 (2): 112-118.

15. Nemeth-Kohanszky M, Matus-Abásolo C, Carrasco-Soto R. Manifestaciones Orales de la Infección por COVID-19. Int J Odontostomat. 2020; 14 (4): 555-560.

16. Baghizadeh-Fini M. Oral saliva and COVID-19. Oral Oncol. 2020; 108: 104821.

17. Carreras-Presas M, Amaro-Sánchez J, López-Sánchez A, Jané-Salas E, Somacarrera-Pérez M. Oral vesiculobullous lesions associated with SARS-CoV-2 infection. Oral Dis. 2021; 27 Suppl 3: 710-712. doi: 10.1111/odi.13382.

18. Sinadinos A, Shelswell J. Oral ulceration and blistering in patients with COVID-19. Evid Based Dent. 2020; 21 (2): 49.

19. Petrescu N, Lucaciu O, Roman A. Oral mucosa lesions in COVID-19. Oral Dis. 2020; 10.1111/odi.13499.

20. Riad A, Gomaa M. Comment on: oral manifestation of COVID-19 as an inaugural symptom? Journal of Oral Medicine and Oral Surgery 2020; 26 (2): 19.

21. Yaumara A, Yayquier D, Leonardo A, Olga G, Orlando L, María S. Infecciones bacterianas asociadas a la COVID-19 en pacientes de una unidad de cuidados intensivos. Rev Med Militar. 2020; 49 (3): e0200793.

22. Cruz-Quintana S, Díaz-Sjostrom P, Arias-Socarrás D, MazónBaldeón G. Microbiota de los ecosistemas de la cavidad bucal. Revista Cubana de Estomatología. 2017; 54 (1): 84-99.

23. Cervera-Ubierna A. Tratamiento de la infección por SARS-CoV-2. Act Pediatr Mex. 2020; 41 (Supl 1): S121-S126.

24. Yarzábal-Rodríguez L, Buela-Salazar L, Sarmiento-Ordoñez J. Técnica de biología molecular para la investigación en odontología y biología oral (1a parte). Rev OACTIVA UC. 2018; 3 (1).

25. Mas E, Poza J, Ciriza J, Zaragoza P, Osta R, Rodellar C. Fundamento de la reacción en cadena de la polimerasa (PCR). Rev AcuaTic. 2016; 15.

26. Garrote-Santana H, Díaz-Alonso C. Reacción en cadena de la polimerasa cuantitativa: del "Nobel" a la actualidad. Rev Cubana Hematol Inmunol Hemoter. 2019; 35 (4): a 1025.

27. Cervantes-Gonzalez J. Obtención de ácido desoxirribonucleico (DNA) útil para análisis genético, a partir de uñas recortadas. Rev Med Hered. 2003; 14 (4): 229-232.

28. Yarzábal-Rodríguez L, Buela-Salazar L, Sarmiento-Ordoñez J. Técnica de biología molecular para la investigación en odontología y biología oral (2a parte). Rev OACTIVA UC. [Internet]. 2019; 4 (3).

29. Orrego-Cardozo M, Parra-Gil M, Salgado-Morales Y, Muñoz-Guarín E, Fandiño-Henao V. Porphyromonas gingivalis y enfermedades sistémicas. CES Odontol. 2015; 28 (1): 57-73.

30. Hoffmeister C, Ducasse K, González M, Quilodrán C, Joyas A. Infección pulmonar y torácica por Fusobacterium nucleatum. Andes Pediatr. 2021; 92 (1): 93-98.
31. Marouf N, Cai W, Said KN, Daas H, Diab H, Chinta VR et al. Association between periodontitis and severity of COVID-19 infection: a case-control study. J Clin Periodontol. 2021; 48: 483-491.

Aspectos éticos: [En el Artículo 17 de la Ley General de Salud (Título segundo, capítulo I) se describe el nivel de riesgo que tienen las investigaciones según la fuente de la que proviene la información que utiliza.

El estudio se realizará de acuerdo con la declaración de Helsinki y con el reglamento de la Ley General de Salud en materia de investigación para la salud: en Título segundo, capítulo I, artículo 17, se considera al estudio sin riesgo, ya que es un estudio que no emplea métodos aleatorios de asignación a esquemas terapéuticos que pongan en riesgo la integridad del paciente.

Este trabajo de investigación se reglamenta bajo las siguientes Leyes Mexicanas: NOM-012-SSA3-2012, Normas técnicas 313, 314 y Ley Federal de Derechos de autor, última reforma DOF 13-01.2016.

Método utilizado para obtener consentimiento informado: No se anexará consentimiento informado con todas sus secciones, de acuerdo con la NORMA Oficial Mexicana NOM-012-SSA3-2012, que establece los criterios para la ejecución de proyectos de investigación para la salud en seres humanos. El apartado 11.3 segundo párrafo menciona: «En los casos de investigaciones sin riesgo o con riesgo mínimo, la carta de consentimiento informado no será un requisito para solicitar la autorización del proyecto o protocolo de investigación» y de acuerdo con los artículos 20, 21 y 22 de la Ley General de Salud en materia de investigación, llevará un aviso de privacidad donde se resumen sus derechos, beneficios posibles, quién investiga y contacto de la universidad. Al decidir participar se considera aceptación voluntaria, informada y libre. Las preguntas no son obligatorias.

Financiamiento: Janeth Lizzett Rodríguez-Cardona.

Correspondencia:

Janeth Lizett Rodríguez Cardona

E-mail: janethrc16@gmail.com 